\title{
S-CONVEX EXTREMAL DISTRIBUTIONS WITH ARBITRARY DISCRETE SUPPORT
}

\author{
Cindy COURTOIS AND Michel DENUIT
}

Abstract. This paper considers the class of $s$-convex stochastic orderings for random variables valued in an arbitrary discrete subset of the half-positive real line. After having established a sufficient condition of crossing-type for these orderings, explicit expressions are derived for stochastic extrema in moment spaces. Some applications in actuarial science are discussed.

Mathematics subject classification (2000): 60E15.

Key words and phrases: Discrete stochastic orderings, arbitrary grid, cut-criterion, stochastic extrema.

\section{REFERENCES}

[1] C. Courtois, \& M. DenuIT, Convex bounds on multiplicative processes, with applications to pricing in incomplete markets, Insurance: Mathematics and Economics, In Press (2007).

[2] C. Courtois, M. Denuit, \& S. VAn Bellegem, Discrete $s$-convex extremal distributions: Theory and applications, Applied Mathematics Letters 19, 1367-1377 (2006).

[3] M. Denut, J. Dhaene, M. Goovaerts, \& R. KaAs, Actuarial Theory for Dependent Risks: Measures, Orders and Models, Wiley, New York (2005).

[4] M. DENUIT, \& CL. LEFÈVRE, Some new classes of stochastic order relations among arithmetic random variables, with applications in actuarial sciences, Insurance: Mathematics and Economics 20, 197-213 (1997).

[5] M. Denuit, CL. Lefìvre, \& M. Mesfioui, On s-convex stochastic extrema for arithmetic risks, Insurance: Mathematics and Economics 25, 143-155 (1999).

[6] M. DenUit, CL. LefÈVRE, \& M. ShaKed, The s-convex orders among real random variables, with applications, Mathematical Inequalities \& Applications 1, 585-613 (1998).

[7] M. DENUIT, CL. LeFÈvRE, \& S. UTEV, Stochastic orderings of (convex/concave)-type on an arbitrary grid, Mathematics of Operations Research 24, 835-846 (1999).

[8] P. C. Fishburn, \& I. H. Lavalle, Stochastic dominance on unidimensional grids, Mathematics of Operations Research 20, 513-525 (Erratum in Vol. 21 p. 252) (1995).

[9] B. HARRIS, Determining bounds on integrals with applications to cataloging problems, The Annals of Mathematical Statistics 30, 521-548 (1959).

[10] B. HARRIS, Determining bounds on expected values of certain functions, The Annals of Mathematical Statistics 33, 1454-1457 (1962).

[11] S. KARLIn, \& A. NoviKOFF, Generalized convex inequalities, Pacific Journal of Mathematics 13, 1251-1279 (1963).

[12] S. KARlin, \& L. S. Shapley, Geometry of moment spaces, Memoirs 12 of the American Mathematical Society, Providence (1953).

[13] S. KARLIN, \& W. J. STUdDEN, Tchebycheff Systems with Applications in Analysis and Statistics. Wiley Interscience, New York (1966).

[14] CL. LeFÈvRE, \& S. UTEV, Comparing sums of exchangeable Bernoulli random variables, Journal of Applied Probability 33, 285-310 (1996).

[15] T. Popoviciu, Sur quelques propriétés des fonctions d'une ou de deux variables réelles, Mathematica 7, 1-85 (1933). 
[16] T. ROLSKI, Order relations in the set of probability distribution functions and their applications in queueing theory, Dissertationes Mathematicae 132, 5-47 (1976).

[17] M. ShaKed, \& J. G. ShanthiKumar, Stochastic Orders and their Applications, Academic Press, New York (1994).

[18] D. SoTYAN, Comparison Methods for Queues and Other Stochastic Models, Wiley, New York (1983).

[19] J. F. WALHIN, \& J. PARIS, On the use of equispaced discrete distributions, Astin Bulletin 28, 241-255 (1998). 